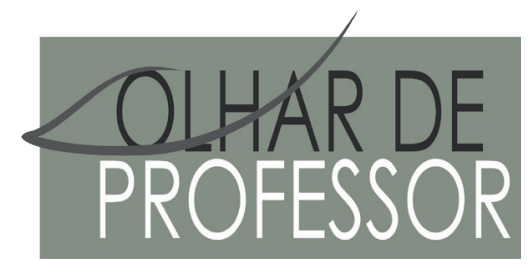

DOI: 10.5212/OLHARPROFR.v.23.2020.15118.209209225339.0513

\title{
PRÁTICAS CORPORAIS DE AVENTURA NA EDUCAÇ̃̃o FÍSICA ESCOLAR E A INCLUSÃO DA CRIANÇA COM DEFICIÊNCIA
}

\author{
BODY ADVENTURE PRACTICES IN SCHOOL PHYSICAL EDUCATION AND THE INCLUSION \\ OF CHILD WITH DISABILITIES
}

\author{
PRÁCTICAS DE AVENTURA CORPORAL EN LA EDUCACIÓN FÍSICA ESCOLAR Y LA INCLUSIÓN \\ DE NIÑOS CON DISCAPACIDAD
}

\author{
MARCOS VINÍCIUS DE PAULA* \\ ANDRÉA KOCHHANN ${ }^{\star *}$
}

\begin{abstract}
Resumo: As reflexões apresentadas neste texto foram elaboradas a partir de experiências corporais inclusivas. O objetivo desse trabalho é discutir sobre a inclusão da criança com deficiência na Educação Física Escolar, por meio das práticas corporais de aventura. Em relação à metodologia, trata-se de um estudo descritivo, do tipo relato de experiência e com abordagem qualitativa. Foram realizados momentos vivenciais de algumas práticas de aventura, bem como foram utilizados a fotografia e o desenho infantil para a análise dos dados. Nesse relato, compartilhamos vivências de três educandos com deficiência desenvolvidas em uma escola da rede municipal de ensino da cidade de Anápolis-Goiás. O estudo aponta que os três estudantes tiveram novas experiências corporais, sendo incluídos e tendo as suas necessidades especiais respeitadas. Destarte, pontuamos que a Educação Física na escola deve oportunizar novos movimentos e novas aprendizagens para as crianças com deficiência.
\end{abstract}

Palavras-chave: Inclusão. Corpo. Deficiência.

\begin{abstract}
The reflections presented in this text were elaborated from inclusive bodily experiences. The objective of this research is to discuss about the inclusion of child with dificiency in School Physical Education, through the adventure bodily practices. Regarding the methodology, it is a descriptive study, of the type experience report and with a qualitative approach. Experiential moments of some adventure practices were carried out, as well as photography and children's drawing were used for data analysis. In this report, we share experiences of three students with deficiency developed in a school of the municipal education system of the city of Anápolis-Goiás. The study points out that the three students had new bodily experiences, being included and having their special needs respected. Thus, we point out that Physical Education at school should provide new movements and new learning for children with deficiency.
\end{abstract}

Keywords: Inclusion. Body. Deficiency.

\footnotetext{
* Doutorando em Educação pela Universidade de Brasília/UnB. Mestre em Educação, Linguagem e Tecnologias pela Universidade Estadual de Goiás/UEG. Especialista em Mídias na Educação pela Universidade Federal de Goiás/UFG. Especialista em Metodologia do Ensino Fundamental pela UFG. Graduado em Educação Física pela ESEFFEGO/UEG. Professor de Educação Física na rede municipal de ensino de Anápolis-GO. E-mail: marcosviniciusguimaraesdepaula@outlook.com

${ }^{* *}$ Pós-doutoranda em Educação pela Pontifícia Católica de Goiás/PUC-GO. Doutora em Educação pela Universidade de Brasília/UnB. Mestre em Educação pela PUC-GO. Docente da Universidade Estadual de Goiás/UEG. Coordenadora do GEFOPI - Grupo de Estudos em Formação de Professores e Interdisciplinaridade. E-mail: andreakochhann@yahoo.com.br
} 
Resumen: Las reflexiones presentadas en este texto fueron elaboradas a partir de experiencias corporales inclusivas. El objetivo de este trabajo es discutir la inclusión de niños con discapacidades en la Educación Física en la Escuela, a través de las prácticas corporales de aventura. En cuanto a la metodología, es un estudio descriptivo, del tipo de informe de experiencia y con un enfoque cualitativo. Se llevaron a cabo momentos experimentales de algunas prácticas de aventura, así como fotografía y dibujo infantil para el análisis de datos. En este informe, compartimos las experiencias de tres estudiantes con discapacidades desarrolladas en una escuela en el sistema educativo municipal de la ciudad de Anápolis-Goiás. El estudio señala que los tres estudiantes tuvieron nuevas experiencias corporales, siendo incluidos y respetando sus necesidades especiales. Por lo tanto, señalamos que la educación física en la escuela debería proporcionar nuevos movimientos y nuevos aprendizajes para los niños con discapacidades.

Palabras clave: Inclusión. Cuerpo. Discapacidad.

\section{INTRODUÇÃO}

A inclusão na escola é um processo político e sensível necessário para o acolhimento de todo ser humano. Seguindo nesta direção, esse artigo discorre sobre a inclusão escolar, contemplando a diversidade por meio do reconhecimento e da valorização das diferenças humanas. Reflete também sobre a ressignificação dos papéis da escola e do educador, para que seja compreendido o valor do desenvolvimento de processos formativos escolares inclusivos.

Esse texto consiste em estudo descritivo, sendo um relato de uma experiência pedagógica, na qual ocorreu a inclusão de três educandos com deficiência, por meio da vivência de práticas corporais de aventura na disciplina de Educação Física, em uma escola da rede municipal de ensino da cidade de Anápolis-Goiás. O objetivo desse trabalho é discutir sobre a inclusão da criança com deficiência na Educação Física Escolar, posicionando a favor da libertação dos padrões controladores aplicados ao corpo.

Assim, o presente artigo almeja colaborar na sensibilização e na conscientização no tocante ao corpo deficiente e, com fundamento em Libâneo (2016), defende uma educação escolar como prática social voltada para a humanização, cujas ações envolvam a pluralidade humana, a fim de garantir a cidadania e o direito da criança com deficiência de movimentar-se e expressar-se. No que diz respeito à fundamentação teórica, Mantoan (2003), Santos (2003), Santos (2008), Barreto e Reis (2011), Reis (2013) e Teixeira (2010) nos ajudaram a debater a inclusão na educação. Já Adorno (2000) e Foucault $(1979,1987)$ nos inspiraram para escrever a respeito do corpo na escola e para debater o espaço do corpo da pessoa deficiente nas aulas de Educação Física.

\section{INCLUSÃONA EDUCAÇÃO ESCOLAR: REPENSANDO A DIVERSIDADE}

Problematizar sobre a diversidade e a inclusão é uma necessidade inadiável do tempo presente para se poder construir uma sociedade inclusiva. Começamos pela difícil tarefa de conceituar a diversidade e de analisar a inclusão, especificamente, no contexto da escola.

A diversidade é estudada por vários campos do conhecimento, contemplando as questões emocionais, físicas, culturais, sociais, dentre outras. De acordo com Barreto e Reis (2011, p. 21), a diversidade é percebida como "[...] variedade e convivência de ideias diferentes, de pessoas diferentes no mesmo espaço onde o paradigma da heterogeneidade sobrepõe o da homogeneidade". Desse modo, a diversidade é percebida dentro do contexto das múltiplas diferenças como as culturais, as religiosas, as sexuais, as ideológicas, as étnicas, dentre outras. A diversidade é um conceito amplo que contempla as múltiplas diferenças que caracterizam o ser humano e que também compõem a sociedade (REIS, 2013).

A diversidade é formada pelas especificidades e pelas semelhanças que unem as relações sociais, sendo ela parte natural da vida (FIGUEIREDO, 2013). Nesse caminho, Díez (2010) discorre que o reconhecimento da diversidade revela que todos os sujeitos humanos possuem condições de aprender independentemente de suas limitações, capacidades, origens e culturas. 
No que tange à inclusão, destacamos que ela é uma prática social aplicada em diversos espaços como no trabalho, na educação, na arquitetura e no lazer, sendo que ela está presente essencialmente na atitude de perceber a si e a outrem (CAMARGO, 2017). A inclusão exige o reconhecimento e a abertura ao outro para perceber a sua capacidade de aprender e der ser. Pressupõe seguir pelas trilhas da cooperação, do encontro e do amor (LIMA, 2006).

Ela é vista como uma luta social para a inserção do cidadão marginalizado nos espaços sociais diversos. É significativo entender que sempre será preciso batalhar pela inclusão social, visto que o sistema capitalista torna a organização social excludente e segregadora. Sobre a inclusão, cabe dizer que ela:

Não é a proposta de um estado ao qual se quer chegar. Também não se resume na simples inserção de pessoas deficientes no mundo do qual têm sido geralmente privados. Inclusão é um processo que reitera princípios democráticos de participação social plena. Neste sentido, a inclusão não se resume a uma ou algumas áreas da vida humana, como, por exemplo, saúde, lazer ou educação. Ela é uma luta, um movimento que tem por essência estar presente em todas as áreas da vida humana, inclusive a educacional. Inclusão refere-se, portanto, a todos os esforços no sentido de garantia da participação máxima de qualquer cidadão em qualquer arena da sociedade em que viva, à qual ele tem direito, e sobre a qual ele tem deveres (SANTOS, 2003, p. 81).

Abordaremos especificamente a inclusão escolar, entendendo-a como uma política voltada para o desenvolvimento de todos, cujo objetivo é possibilitar a convivência dos educandos com necessidades especiais com seus pares, potencializando o seu desenvolvimento e o aprendizado de todos (SILVA; GAIATO; REVELES, 2012). A inclusão na escola permite desconstruir os medos em relação à diversidade, nos ensina a cuidar uns dos outros e nos mostra que ao convivermos com as diferenças nós aprendemos, crescemos e podemos ajudar a construir uma sociedade mais solidária.

É oportuno reconhecer que as diferenças fazem parte da vida escolar. Ora, são as diferenças que caracterizam um espaço social qualquer formado por seres humanos. A escola, por conseguinte, é um lugar onde as diferenças existem e se relacionam. Escola e diversidade estabelecem uma relação intrínseca. A esse respeito, salientamos que:

A diversidade não pode ser concebida como algo externo, de fora, do outro, mas como parte de cada um - identidade, pois, embora sejamos diferentes, somos parte de uma mesma cultura uma igualdade repleta de diferenças. Uma mesma cultura não no sentido totalitário, universal, mas, sobretudo, uma mesma cultura plural, multiforme, complexa, contínua e indeterminada. Somos seres diferentes e semelhantes ao mesmo tempo e é essa complexidade que nos faz sermos únicos: seres uni-pluri-multi. No campo educacional, a diversidade se faz presente na manifestação da diferença no cotidiano. Embora cada escola seja única por conter diferentes pessoas, estruturas, problemas, dificuldades e tantas outras particularidades, constitui-se em um universo de diferenças. Assim, modos de agir, interagir, relacionar, experimentar, expressar, são diferenças que perfazem a identidade (TEIXEIRA, 2010, p. 184).

Nesse seguimento, precisamos de uma escola acolhedora das diferenças, sendo fundamental desenvolvermos processos formativos inclusivos. Para isso, segundo Mantoan (2003, p. 43), temos que: "[...] reconhecer as diferentes culturas, a pluralidade das manifestações intelectuais, sociais e afetivas; enfim, precisamos construir uma nova ética escolar”. Propor uma educação escolar inclusiva implica no reconhecimento da cidadania e dos direitos de todo educando.

A escola precisa ser vista “[...] como uma instituição voltada para a realização da prática pessoal e social” (SANTOS, 2008, p. 147), deixando de ser um ambiente de exclusão e de reprodução do preconceito para tornar-se uma escola para todos, ou seja, um espaço de cidadania e de emancipação dos sujeitos (ALMEIDA; TEIXEIRA, 2011).

Pensando em uma escola cidadã e inclusiva é primordial o desenvolvimento de um fazer pedagógico que contemple as diferenças por parte dos docentes. Nessa direção, Levinas (1980) alerta para o reconhecimento das diferenças no processo educacional. A inclusão somente será possível se o outro for reconhecido, acolhido e amado. É essencial um olhar para o outro, sendo que: 
Abordar outrem no discurso é acolher a sua expressão onde ele ultrapassa a cada instante a idéia que dele tiraria um pensamento. É, pois, receber de Outrem para além da capacidade do Eu; o que significa exatamente: ter a idéia do infinito. Mas isso significa também ser ensinado. A relação com Outrem ou o discurso é uma relação não alérgica, uma relação ética, mas o discurso acolhido é um ensinamento. O ensinamento não se reduz, porém à maiêutica. Vem do exterior e traz-me mais do que eu contenho (LEVINAS, 1980, p. 37-38).

Daí a relevância das práticas pedagógicas marginais de inclusão na educação escolar. Esse estudo compreende por práticas marginais inclusivas as ações que mesmo pequenas são significativas e colaboram para incluir os sujeitos esquecidos e excluídos. Não há mais espaço para uma escola desumana e excludente.

Para refletir sobre uma escola "outra”, que se preocupa em inserir todo ser humano nos processos de formação, o paradigma da igualdade deve dar espaço para o paradigma da diversidade (BARRETO; REIS, 2011), visto que o ser humano é ímpar e nunca será igual ao outro. Essa percepção é pertinente para a desconstrução dessa escola padronizadora que está posta. Uma escola inclusiva resiste e transgride a modelagem dos seres humanos, reconhecendo a diversidade.

Quanto aos processos de ensino e de aprendizagem, Barreto e Reis (2011) elencam que muitos educandos são considerados anormais por não corresponderem a um arquétipo de aprendizagem. Isso nega a individualidade do estudante, negligenciando e desconsiderando as suas diferenças. Uma sala de aula não pode ser uma forma padronizadora, mas sim um grande círculo vivencial que respeita cada sujeito em suas particularidades.

Sendo assim, verificamos que os educadores necessitam diversificar as formas de ensino, respeitando os diferentes ritmos de aprendizagem dos discentes. De acordo com Barreto e Reis (2011), cada estudante apresenta desempenhos distintos na relação com o conhecimento e em seu fazer pedagógico, o professor, necessita reconhecer essa diversidade para que os aprendizes sejam respeitados e conquistem progressos em sua aprendizagem.

Vale ressaltar que algumas medidas são fundamentais para se efetivar uma educação inclusiva na escola, dentre as quais se destacam: a adequação do espaço físico, tornando-o acessível; o uso de materiais didáticos diferenciados e de tecnologias; a formação teórico-prática consolidada dos profissionais envolvidos. Além dessas, Barreto e Reis (2011, p. 30) citam:

Conteúdos curriculares vinculados à realidade histórico-cultural dos alunos; o sistema de avaliação como elemento facilitador e promotor de aprendizagens; a valorização do educador como profissional competente para trabalhar esse conteúdo de forma contextualizada e significativa; a qualidade das relações que se estabelecem no espaço escolar, respeitando as diferenças e o lugar da emoção nessas interações, haja vista que a organização conceitual do lugar da emoção tem estado ausente das teorias de aprendizagem.

Uma escola sensível é possível. Contudo, necessitamos repensar para que serve a instituição escolar, a educação e a atuação docente. Conforme afirma Mantoan (2003, p. 43), carecemos "ressignificar o papel do professor, da escola, da educação e de práticas pedagógicas que são usuais no contexto excludente do nosso cotidiano, em todos os seus níveis”. Por isso verifica-se a importância de experiências pedagógicas que tragam para a cena os atores escolares esquecidos, pois esses sujeitos são humanos e merecem serem vistos e ouvidos. A escola é um espaço de formação humana e não de deformação, não pode esquecer e silenciar o humano. Devemos, na verdade, cuidar uns dos outros, uma vez que nos realizamos no encontro. A esse respeito, defendemos a escola:

[...] Como espaço de humanização social e de compartilhamento do mundo plural. Esse espaço precisa se transformar em um ambiente estimulador das potencialidades de todos os alunos. Com isso, a diversidade, em suas diversas nuances, será vista como um aspecto positivo no processo educativo despertando em todos - alunos com diferenças de natureza biológica, relacional, motivacional, social e/ou cultural - o espírito de pertença (SANTOS, 2017, p. 24).

Dessa forma, avaliamos ser elementar o reconhecimento e a valorização da diversidade no âmbito escolar para um convívio social harmonioso. Afinal, a escola não é apenas para alguns. Meirieu (2005) 
afirma que a vocação dessa instituição social é ser aberta para todos. Destaca ainda que ela deve ser “[...] uma instituição que tem a preocupação de não descartar ninguém, de fazer com que se compartilhem os saberes que ela deve ensinar a todos. Sem nenhuma reserva” (MEIRIEU, 2005, p. 44).

A escola é um espaço de produção e de socialização do conhecimento científico, afetivo, estético e moral (LIBÂNEO, 2016). E assim, além de trabalhar os conhecimentos produzidos historicamente, ela precisa ser um espaço de compreensão humana (MORIN, 2017), onde sejam ensinados e apreendidos o cuidado, o zelo e o respeito pelo outro, objetivando a transformação pessoal de cada educando e da sociedade. Portanto, a escola deve voltar-se para o desenvolvimento social e humano.

Desse modo, a escola precisa possibilitar um encontro afetuoso de seres diferentes. Desejamos um ambiente escolar político e humano que contemple as diferenças, entendendo que para o desenvolvimento de práticas pedagógicas inclusivas é crucial uma formação inicial e continuada que considere a diversidade.

\section{BREVE ANÁLISE SOBRE A FORMAÇÃO DE PROFESSORES NA PERSPECTIVA INCLUSIVA}

Entendemos que são imprescindíveis políticas públicas educacionais que contemplem a formação de professores na perspectiva inclusiva; a aquisição de materiais específicos para o trabalho pedagógico com os educandos com deficiência; a adequação do espaço físico da escola, dentre outros aspectos. Não se constrói uma escola inclusiva sem investimentos dignos. E não se faz uma educação inclusiva apenas no discurso. Uma educação escolar cidadã é feita por meio de políticas públicas sérias que visam à constituição de uma sociedade justa e democrática. Sobre isso, Costa (2012, p. 90) destaca que:

Refletindo sobre a importância do fortalecimento da democracia por intermédio da educação e as possibilidades de emancipação do indivíduo, justifica-se a implementação de políticas públicas de educação e formação de professores, decorrentes da legislação vigente que se inserem no atendimento às demandas sociais.

Em relação especificamente à formação de professores, elencamos que é basilar uma perspectiva de formação docente que "[...] vislumbre a transformação da escola em um espaço de cidadania para alunos de todas as raças, gêneros, classes sociais e padrões sociais” (CANEN, 2001, p. 224). A formação inicial e permanente desempenha papel vital na inclusão, pois permite que o professor seja sensibilizado no que concerne às diferenças, ajudando-o a perceber a seriedade da sua função social para a construção de uma sociedade melhor.

Pelos movimentos de formação, o professor terá conhecimento que permitirá a percepção de sua atuação política. Embora o foco desse texto seja o trabalho docente, faz-se necessário pontuar que não são apenas os professores que precisam de formação no tocante à educação escolar inclusiva. Toda a equipe escolar precisa de preparação para atuar nos processos de inclusão, uma vez que a educação não ocorre apenas na sala de aula, mas em todos os espaços-tempos escolares. Sobre isso, Correia (2008, p. 28) elenca que:

Os educadores, os professores e os auxiliares de ação educativa necessitam de formação específica que lhes permita perceber minimamente as problemáticas que seus alunos apresentam, que tipo de estratégia devem ser consideradas para lhes dar resposta e que papel devem desempenhar as novas tecnologias nestes contextos.

Concordamos ainda que para desenvolver processos de inclusão na educação escolar é relevante atentar-se para:

A necessidade de formação e informação dos profissionais da educação acerca das questões ligadas a dialética inclusão/exclusão, principalmente, no que se refere às culturas, políticas e práticas que potencializam uma relação educativa mais ou menos inclusiva. Neste sentido, a compreensão da diversidade favorece a flexibilização do pensar, sentir e agir para a valorização da mesma, minimizando os processos excludentes. É necessário, portanto, investir no desenvolvimento de culturas institucionais que primem pela valorização das diferentes formas de existir de todos os seus sujeitos; em políticas de formação que estimulem a discussão acerca 
desta diversidade; mobilizar esforços, para desenvolver práticas que levem à inclusão, através do desenvolvimento de situações de ensino e aprendizagem que estimulem a mudança de uma cultura excludente. (SANTOS, s.d., p. 17)

A formação de professores não garante sozinha a qualidade profissional, tampouco é o suficiente para que a inclusão escolar ocorra. Entretanto, ela é um aspecto relevante e decisivo para que uma educação escolar verdadeiramente inclusiva possa acontecer, assegurando o respeito à diversidade (PLETSCH, 2009; TERRA; GOMES, 2013). Os cursos de formação de professores necessitam sensibilizá-los para que os mesmos possam perceber que há dois caminhos para o seu trabalho: incluir ou excluir. Segundo Mantoan (2003, p. 25), "todos os níveis de formação de professores devem sofrer modificações nos seus currículos, de modo que os professores aprendam práticas de ensino adequadas às diferenças”.

Na concepção de Martins (2011) é fundamental que os docentes tenham conhecimento sobre as particularidades especiais dos estudantes, de tal modo que saibam lidar com eles e possam colaborar para avanços e aprendizagens. Destarte, ressignificar a formação dos educadores é urgente, visto que ela ajudará na produção de novos sentidos e novos significados para a escola e para a própria vida, que por sua vez contribuirão para a inclusão em educação. Sobre isso, vale destacar o papel da universidade como espaço de formação sólida de docentes. Ela é o lugar privilegiado para uma formação conectada com as demandas sociais contemporâneas com vistas à humanização (MORIN; DÍAZ, 2016), sendo a inclusão escolar uma dessas.

No contexto específico da Educação Física, Bueno (1993) afirma que professores bem preparados conseguem identificar os desejos e as necessidades educacionais dos estudantes com deficiência, podendo pensar ações pedagógicas que possibilitem o educando ser incluído em atividades junto ao coletivo da sala e também em atividades individuais, sendo feitas as alterações e as adaptações necessárias. Conforme Goffredo (1997), a formação em Educação Física deve assegurar conteúdos referentes à diversidade como um todo e às deficiências, bem como conhecimentos didático-pedagógicos que ajudem a pensar em atividades inclusivas.

Nesta continuidade, a partir desse momento passamos a problematizar a inclusão no contexto da disciplina de Educação Física, relatando uma experiência pedagógica desenvolvida em uma escola da rede municipal de ensino de Anápolis-Goiás, na qual dois educandos com deficiência visual e um com deficiência intelectual foram incluídos nas vivências corporais propostas. É propósito desse texto questionar: qual o espaço do corpo da pessoa com deficiência nas aulas de Educação Física?

\section{INCLUSÃO NA EDUCAÇÃO FISICA ESCOLAR: COMPARTILHANDO AVENTURAS}

O espaço do corpo na escola nunca foi privilegiado. O lugar do corpo na escola ainda é secundário e marginalizado. Para Foucault (1979), o corpo é um espaço de conflitos e é atravessado pela ideologia dominante que impõe o seu adestramento disciplinar.

Segundo Foucault (1979), o controle dos indivíduos começa pelo corpo, uma vez que a ideologia se manifesta nele. Essa influência controladora acaba por modelar e padronizar os corpos humanos, excluindo os que não se adequam às normatizações do corpo. $\mathrm{O}$ trecho a seguir da obra do autor nos permite raciocinar sobre as relações de poder aplicadas ao corpo, inclusive das crianças, e os mecanismos controladores do corpo.

O domínio, a consciência de seu próprio corpo só puderam ser adquiridos pelo efeito do investimento do corpo pelo poder: a ginástica, os exercícios, o desenvolvimento muscular, a nudez, a exaltação do belo corpo... tudo isto conduz ao desejo de seu próprio corpo através de um trabalho insistente, obstinado, meticuloso, que o poder exerceu sobre o corpo das crianças, dos soldados, sobre o corpo sadio (FOUCAULT, 1979, 146).

Assim sendo, pode-se afirmar que a escola colabora para a modelagem, o arrebanhamento e a docilidade dos corpos. Existe um projeto biopolítico para docilizar e padronizar os corpos, pois “[...] o corpo também está diretamente mergulhado num campo político; as relações de poder têm alcance 
imediato sobre ele; elas o investem, o marcam, o dirigem, o supliciam [...]" (FOUCAULT, 1987, 28). E desse modo, o corpo da pessoa com deficiência é excluído por não pertencer e não atender aos padrões sociais dominantes.

No entanto, concordamos com Adorno (2000) ao dizer que não temos o direito de modelar as pessoas. Concebemos que é necessário resistir bravamente à modelagem dos corpos humanos, lutando para libertar os padrões aplicados a ele. Nesse sentido, entramos na batalha por uma visibilidade política dos corpos das pessoas com deficiência, tratando mais especificamente do caso da disciplina de Educação Física.

Na concepção de Kunz (1994), a Educação Física trata na escola de uma área denominada cultura de movimento humano, enquanto que para o coletivo de autores (1992), ela tematiza a chamada cultura corporal. Portanto, a Educação Física aborda as vivências do corpo, isto é, as práticas corporais como as danças, as lutas, as ginásticas, o circo, o teatro, os esportes, os jogos, as brincadeiras, as práticas de aventura, dentre outras. O conceito de práticas corporais remete ao conjunto de manifestações culturais construídas historicamente e expressas pelo corpo (SILVA et al., 2009; LAZZAROTTI FILHO et al., 2010). Ademais, nesse trabalho, o entendimento de práticas corporais de aventura corresponde ao conjunto de conhecimentos que ocorrerem no meio urbano ou na natureza, podendo levar a experiências corporais radicais (FRANCO; CAVASINI; DARIDO, 2014).

Nessa direção, no contexto da Educação Física escolar, questiona-se: há corpos que podem participar das aulas de Educação Física na escola? E há corpos que não podem participar? Os estudantes com deficiência devem ser retirados da aula de Educação Física e retornar ao convívio com a turma quando a aula acabar? As vivências corporais da Educação Física são destinadas a quais corpos? Essas indagações nos convidam a dialogar sobre o processo inclusivo nas práticas corporais da Educação Física Escolar.

O espaço do corpo do educando com deficiência nas aulas de Educação Física não pode ser o da marginalização, o do esquecimento e o da exclusão. $\mathrm{O}$ aluno com deficiência tem o direito de participar das aulas e ter acesso ao conhecimento da Educação Física. Trata-se de uma questão acima de tudo de sensibilidade.

Os corpos desses aprendizes precisam ser exibidos, explicados e respeitados. É importante tratar da humanidade do corpo da pessoa com deficiência para incluí-lo e também educar os outros estudantes e toda a equipe escolar. Temos que lutar para a conscientização a respeito do corpo da pessoa com deficiência, ajudando toda comunidade escolar a depreender que todo corpo é um corpo cidadão. A inclusão de crianças com deficiência contempla a diversidade e também fortalece a democracia (COSTA, 2012).

Logo, defendemos uma atuação dos professores de Educação Física como educadores críticos do corpo, resistindo à perversidade da exclusão da pessoa com deficiência. Adorno (2000, p. 183) nos chama bastante atenção ao anunciar sua crítica: “[...] a única concretização efetiva da emancipação consiste em que aquelas poucas pessoas interessadas nesta direção orientem toda a sua energia para que a educação seja uma educação para a contradição e a resistência”. Nesse sentido, urge desenvolver uma Educação Física transgressora e acolhedora de toda pessoa com deficiência.

Cabe frisar que trabalhar com os corpos deficientes não é uma tarefa simples. Pontuamos que exigem cuidados necessários como a adequação do espaço físico, materiais didáticos específicos em alguns casos, auxílio de profissionais para o cuidado do aluno, dentre outros aspectos. No entanto, o corpo da pessoa deficiente jamais pode ser abandonado e preterido. Nesse caminho, passamos a compartilhar uma intervenção pedagógica inclusiva realizada na disciplina de Educação Física, por meio de práticas corporais de aventura. Essa investigação aconteceu em uma escola municipal de Anápolis-GO.

No que tange aos caminhos metodológicos, o presente trabalho tem abordagem qualitativa (FLICK, 2009) e consiste, tomando como referência as ideias de Gil (2008), em um estudo descritivo do tipo relato de experiência. Para Bogdan e Biklen (1994), processos descritivos têm o ambiente natural como fonte de dados e o pesquisador como principal instrumento de pesquisa.

A fotografia foi utilizada como técnica de coleta de dados para realizar registros da experiência em questão e também como instrumento de análise de resultados (SANTOS, 2000), colaborando para refletir sobre a inclusão da criança com deficiência. Vale ressaltar que houve autorização dos responsáveis para a divulgação das imagens presentes nesse estudo e que ainda assim os rostos das crianças e dos 
adultos foram desfocados. Ademais, o desenho teve grande importância nesse estudo, uma vez que ele é um importante caminho metodológico em pesquisas cujos sujeitos são crianças. O uso do desenho na metodologia visa reconhecer a criança como sujeito criativo, possuidor de sentimentos e de emoções. Para Corsaro (2011), os desenhos são técnicas importantes para pesquisas e estudos com crianças, visto que por eles a criança se expressa e comunica-se. Dessa forma, será feita uma breve análise dos desenhos das crianças envolvidas.

Nessa intervenção, dois professores de Educação Física da unidade escolar em questão trabalharam com o conteúdo relacionado às práticas corporais de aventura, com as turmas de primeiro ano ao oitavo ano do ensino fundamental. Os objetivos principais dessa ação pedagógica eram apreender que existem várias formas de práticas corporais de aventura e vivenciar algumas delas. Para isso, os educadores elaboraram uma aula sobre a temática (duas turmas por aula), na qual contaram com o apoio de uma ONG chamada Impacto Aventuras, que disponibilizou todo material e conduziu a atividade. Destacamos que todo o material foi conferido pela equipe especializada da ONG para garantir a segurança dos educandos.

Durante a aula, os estudantes foram divididos em grupos para vivenciar algumas atividades de aventura, dentre as quais destacamos:

A) O slackline, que é uma fita elástica esticada entre dois pontos fixos, o que permite ao praticante andar e fazer manobras por cima;

B) O arvorismo, que é denominado pelos estrangeiros de "canopy”, cuja livre tradução para o português significa toldo ou cobertura. Portanto, o arvorismo é uma prática corporal realizada na copa das árvores;

C) A cama elástica;

D) A escalada em paredão fixo;

F) A escalada em material inflável.

Nas figuras de um a quatro seguintes, podemos observar algumas imagens da experimentação das atividades de aventura feita pelos educandos.

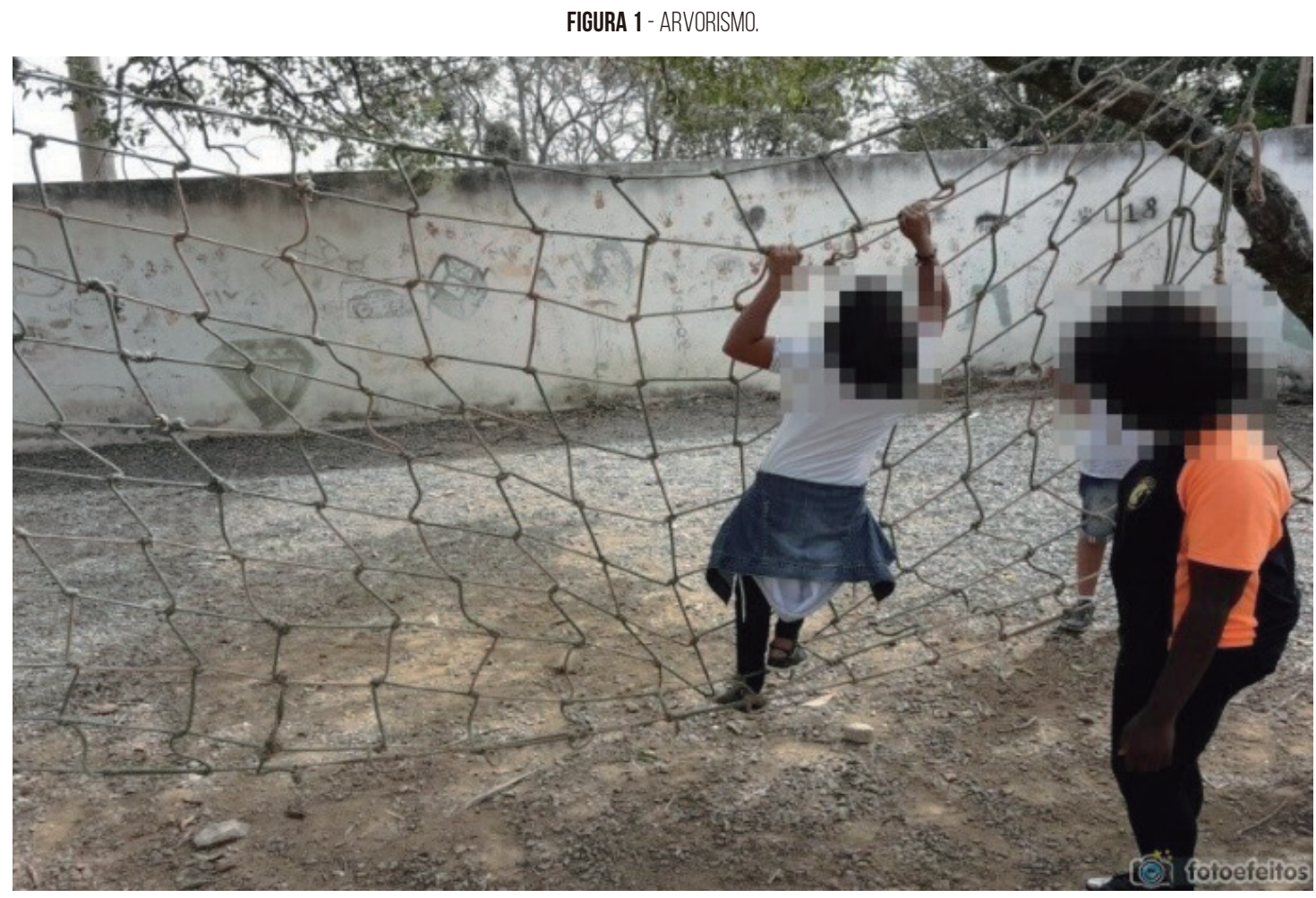

FONTE: ACERVO DOS AUTORES. 
FIGURA 2 - ESCALADA NO MATERIAL INFLÁVEL.

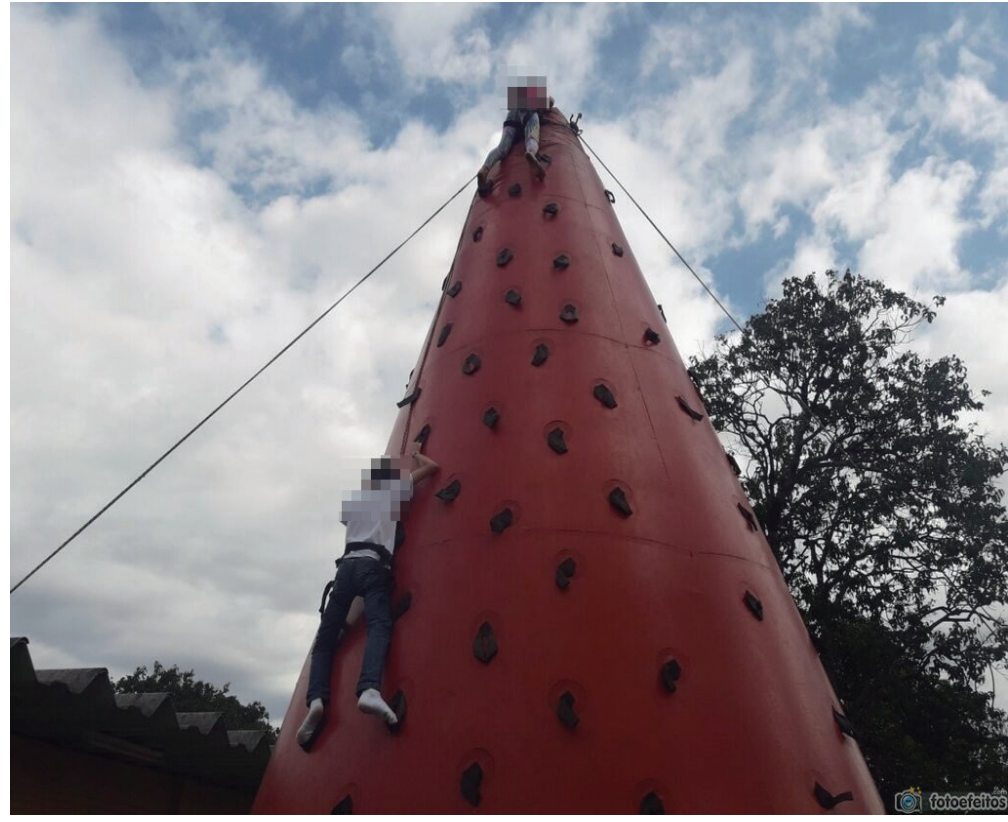

FONTE: ACERVO DOS AUTORES

FIGURA 3 - ESCALADA NO PAREDÃO.

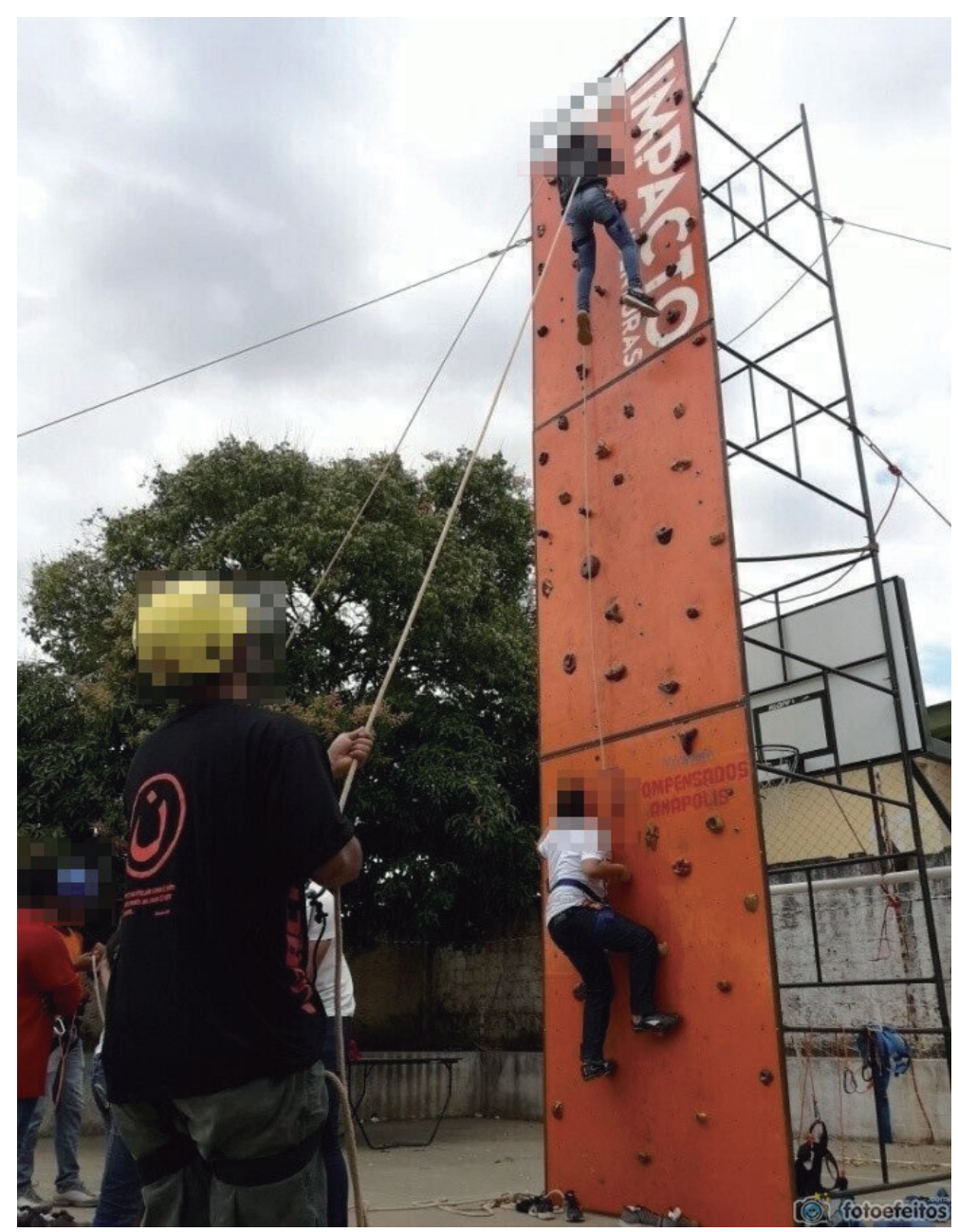

FONTE: ACERVO DOS AUTORES. 


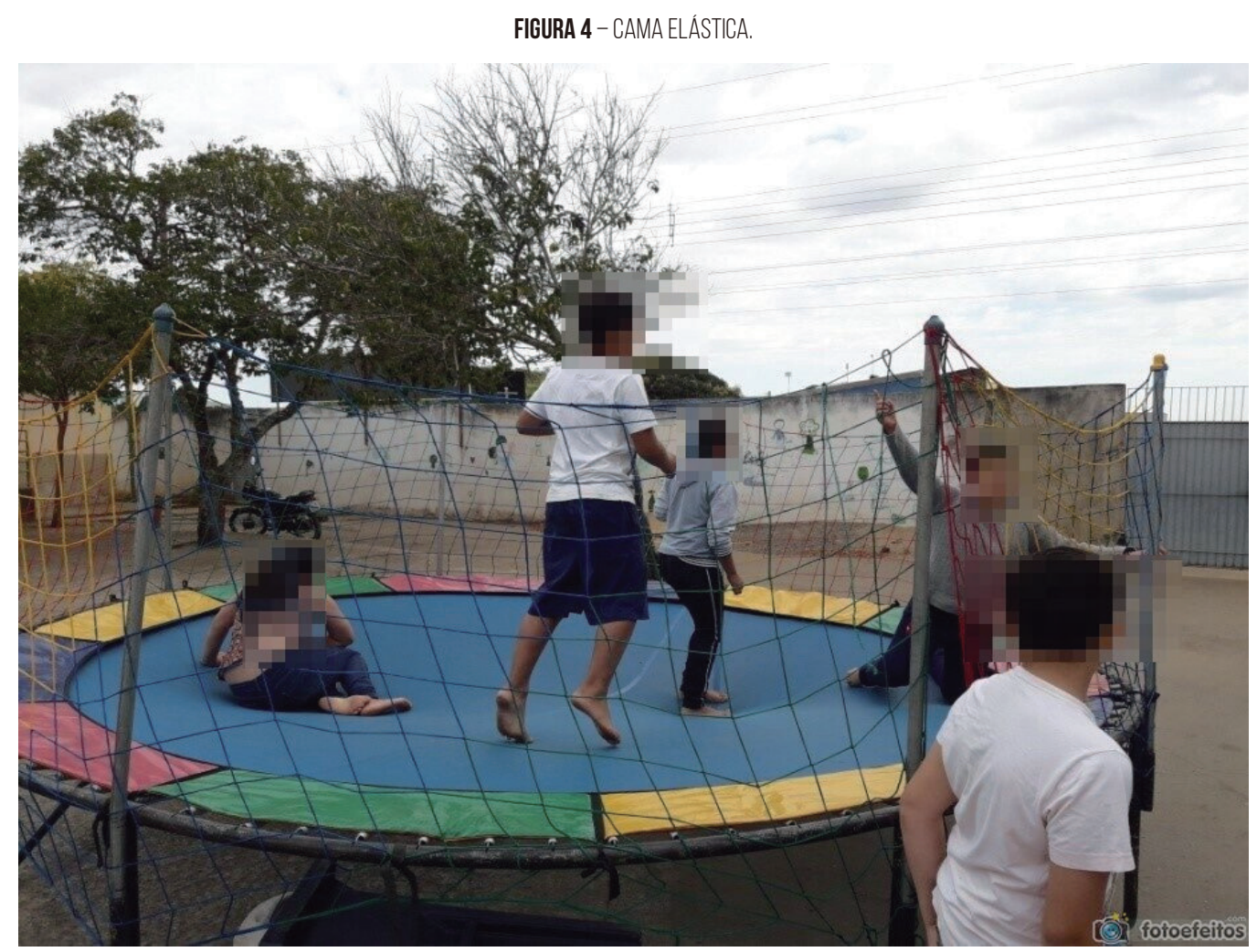

FONTE: ACERVO DOS AUTORES.

\section{VIVÊNCIAS INCLUSIVASE DISCUSSÕES}

Verificamos que essas atividades eram desconhecidas para a grande maioria dos aprendizes que pertencem às camadas populares e nem sempre têm acesso a esse tipo de vivência. Por conseguinte, averiguamos que foi um momento de descoberta para os educandos e a Educação Física cumpriu seu papel social de oportunizar experiências corporais.

Avaliamos que o trabalho realizado foi expressivo e valioso para todos os estudantes. Entretanto, como o objetivo desse texto é discutir a inclusão escolar, focaremos nas experiências com os educandos com deficiência. Participaram das atividades propostas duas crianças com deficiência visual, sendo um educando cego total de um olho e com baixa visão do outro (terceiro ano do ensino fundamental), uma educanda também cega total de um olho e com baixa visão do outro (quinto ano do ensino fundamental) e ainda um educando com deficiência intelectual (sexto ano do ensino fundamental).

Quando iniciamos as atividades, alguns estudantes e alguns professores questionaram sobre o que seria feito com os estudantes especiais, com quem eles ficariam e onde ficariam. Essas indagações nos fizeram pensar sobre: quais corpos podem participar das aulas de Educação Física e em especial das práticas corporais de aventura?

Os professores de Educação Física e a equipe de trabalho da ONG afirmaram que todos os estudantes iriam participar das atividades, respeitando as diferenças de cada um. Cabe deixar claro que esses educandos com deficiência participam das aulas de Educação Física cotidianamente, sendo respeitadas as suas limitações, e não apenas quando ocorrem atividades específicas como as que aqui estão sendo relatadas.

Sobre as vivências, enfatizamos que a aluna deficiente visual brincou várias vezes na cama elástica, tanto que a mesma não saía da fila do brinquedo. Importante mencionar que ela foi devidamente acompanhada por uma professora e também por colegas de sala. Foi emocionante perceber a alegria dessa educanda ao saltar na cama elástica, que para ela era uma grande aventura. Seus gritos de alegria e seus sorrisos foram intensos. Consideramos que essa simples experiência para a aluna foi uma aventura 
transformadora e marcante para o seu corpo. Quando brincava na cama elástica ela disse ao seu professor de Educação Física: "Parece que estou voando".

Desse modo, a reação da educanda nos instiga a refletir a respeito da escola ser um espaço que permita as crianças e os jovens com deficiência voarem. É imperativo romper com as gaiolas da escola e da vida, pois o que se vê muitas vezes é a escola cortando as asas desses seres humanos. A experiência com essa estudante vai ao encontro do que foi discutido por Meirieu (2005): a escola deve ensinar a todos, sem descartar ninguém. Ora, nenhum ser humano é descartável.

Alicerçados em Bogdan e Biklen (1994) sobre o uso da fotografia na pesquisa científica, destacamos que as figuras 5 e 6 apresentadas a seguir servem para revelar as informações sobre o comportamento dos sujeitos pesquisados, a interação desses com as outras pessoas envolvidas e como os sujeitos se apresentam em diversas situações.

O aluno com deficiência intelectual também brincou muito na cama elástica e, da maneira como conseguiu, participou do arvorismo. Em todas as atividades ele foi acompanhado pelo seu professor de Educação Física e pela equipe da ONG. Constatamos que o aluno estava muito alegre com as novas e desafiadoras atividades. Seu corpo não foi esquecido e foi incluído, sendo respeitadas as suas especificidades, de tal forma que as atividades foram realizadas de forma mais devagar. Advertimos que não permitir que ele participasse da aula seria um absurdo e um ato de negação ao conhecimento e às descobertas do corpo e da vida.

\section{FIGURA 5 - ALUNO COM DEFICIENCIA INTELECTUAL NA CAMA ELÁSTICA.}

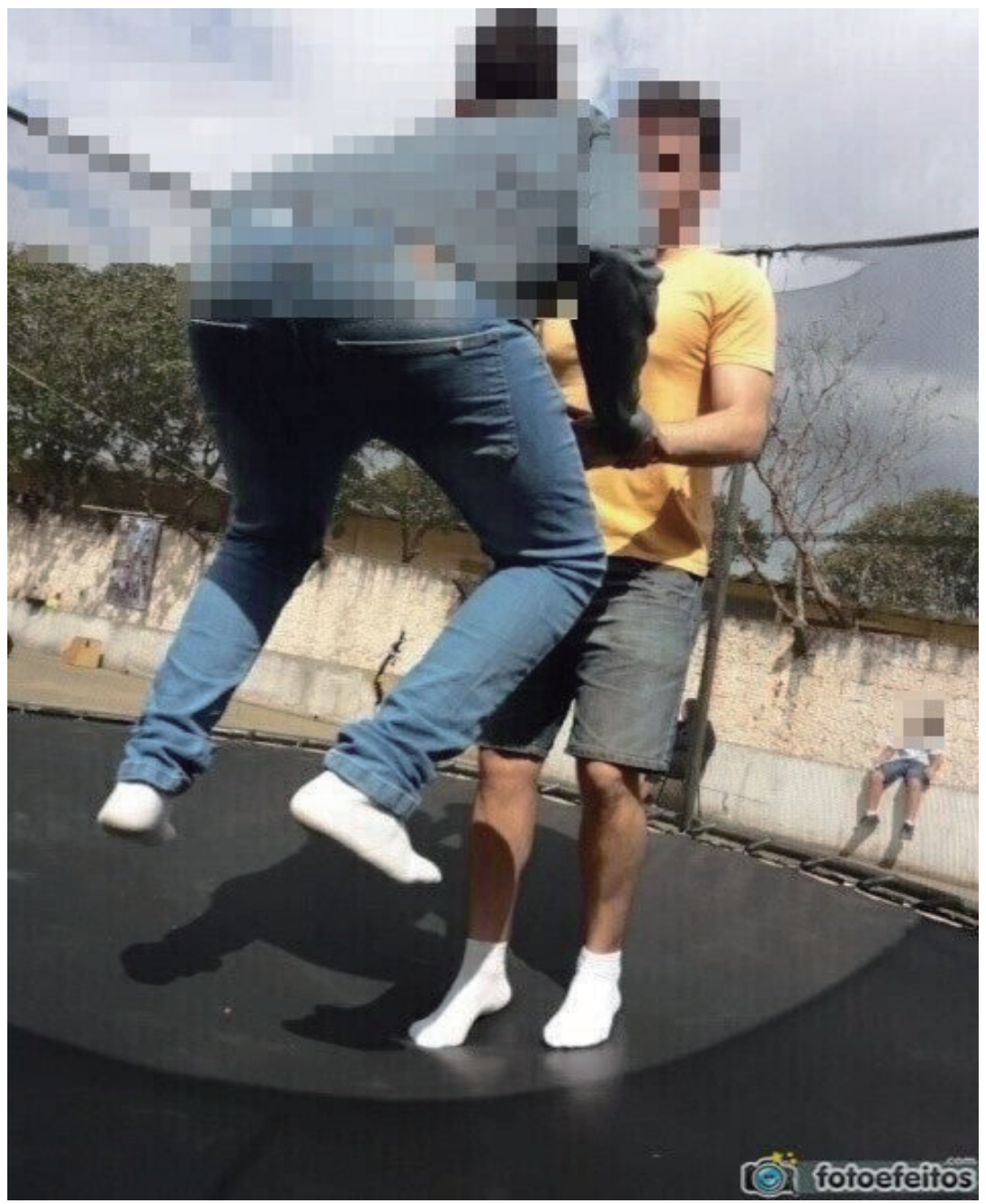

FONTE: ACERVO DOS AUTORES. 
Na figura 5 podemos verificar o educando vivenciando os movimentos corporais na cama elástica e sendo apoiado pelo seu professor de Educação Física, que lhe garantiu segurança para o desenvolvimento da atividade e procurou ressignificar o papel de educador e da prática pedagógica (MANTOAN, 2003) na Educação Física, ampliando as vivências motoras do educando com deficiência intelectual.

O estudante deficiente visual (cego de um olho e com baixa visão do outro) participou de todas as atividades e surpreendeu a todos quando chegou ao topo da escalada fixa. Ele demorou um pouco mais para completar a escalada, mas respeitamos o seu ritmo, sem cobrar que ele fosse rápido, como nos sugere Barreto e Reis (2011) ao nos alertar sobre o respeito aos ritmos particulares de aprendizagem da cada educando. Ele parou, sentiu medo, retornou a subir, até que venceu o paredão de aproximadamente 7,5 metros de altura, sendo que os professores e a equipe da ONG incentivaram o educando a não desistir, já que perceberam que ele conseguiria vencer o desafio dessa aventura. Na figura abaixo podemos constatar a conquista desse educando no paredão de escalada.

FIGURA 6 - ALUNO COM DEFICIENCIA VISUAL NA ESCALADA.

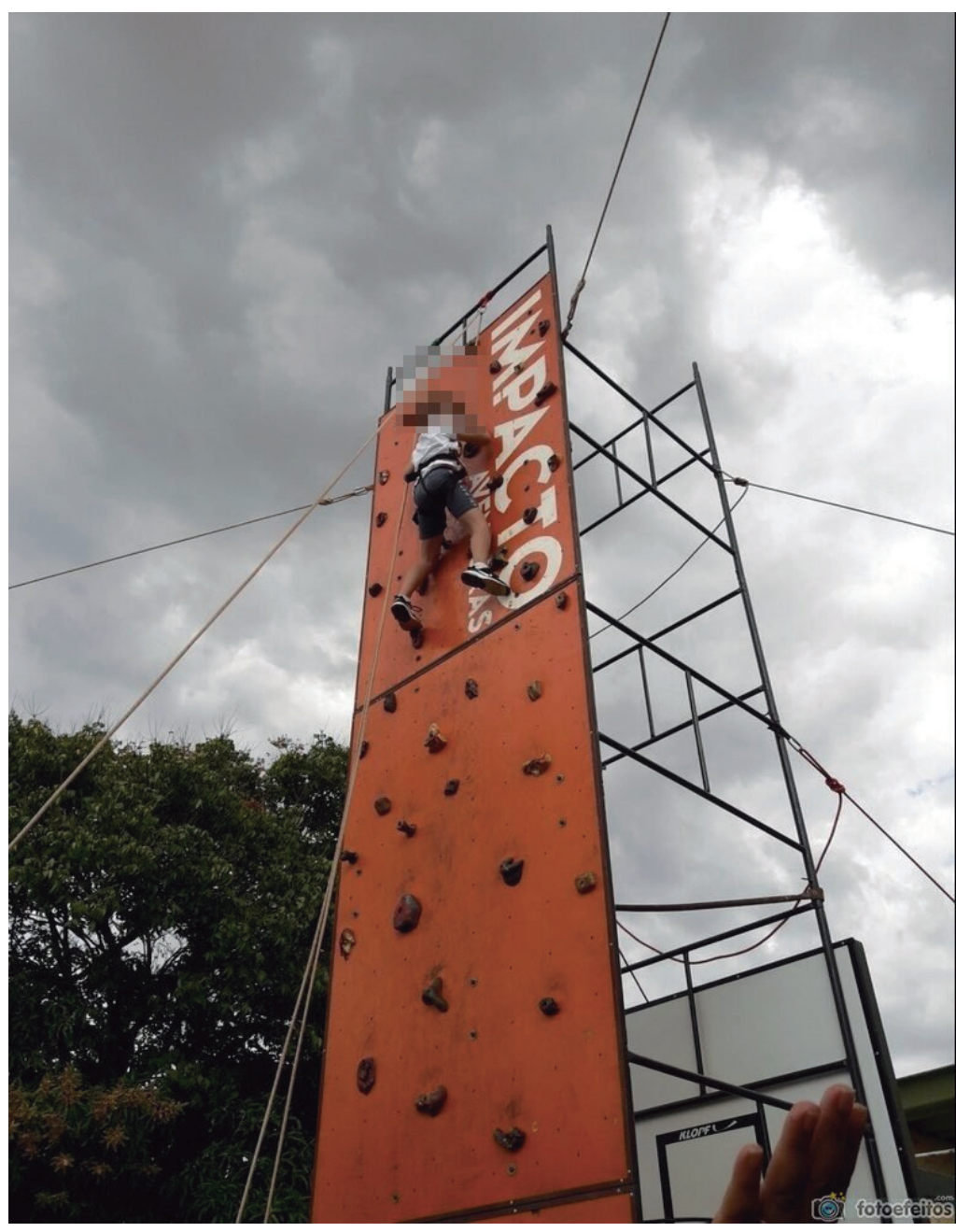

FONTE: ACERVO DOS AUTORES.

Na aula posterior às vivências das práticas de aventura, os educandos produziram um desenho retratando as experiências corporais vividas. Sabe-se que o desenho é bastante utilizado nos estudos com crianças (CORSARO, 2011), uma vez que por ele a criança se expressa com liberdade. Além disso, cabe pontuar que o uso do desenho com crianças possibilita trabalhar uma educação estética, isto é, uma educação das sensibilidades. Ao desenhar, o educando pode expressar a sua arte e a sua subjetividade, posto que enxergamos que cada aluno é artista de sua própria história. A escola que queremos é uma escola que considere a sensibilidade e as emoções, ensinando os conhecimentos e tocando também os 
corações. No que se refere à escola, pontua-se que a sensibilidade humana não pode ser esquecida nos processos formativos escolares (NICOLESCU, 2005).

Vejamos a seguir o desenho da aluna deficiente visual que a retratou na cama elástica.

FIGURA 7 - PRODUÇÃO ARTISTICA DA ALUNA DEFICIENTE VISUAL.



FONTE: ACERVO DOS AUTORES.

Podemos inferir que a aluna desenhou a si e aos seus professores e colegas que a acompanharam na cama elástica, como ela mesmo relatou ao ser questionada sobre o desenho. Analisamos que esse momento vivencial possibilitou que o seu corpo fosse visualizado e respeitado. A atividade permitiu que a aluna voasse, mesmo que por alguns instantes. E essa é uma das intenções desse estudo: mostrar que os estudantes com deficiência possuem o direito de voar, cabendo aos seus responsáveis e aos demais atores escolares a tarefa de os estimularem em novos e lindos voos.

A seguir, visualizamos a produção artística do aluno deficiente visual que se aventurou na escalada e registrou esse momento com muitas cores, fazendo uso de sua lupa eletrônica. 
FIGURA 8 - DESENHO DO ALUNO DEFICIENTE VISUAL.

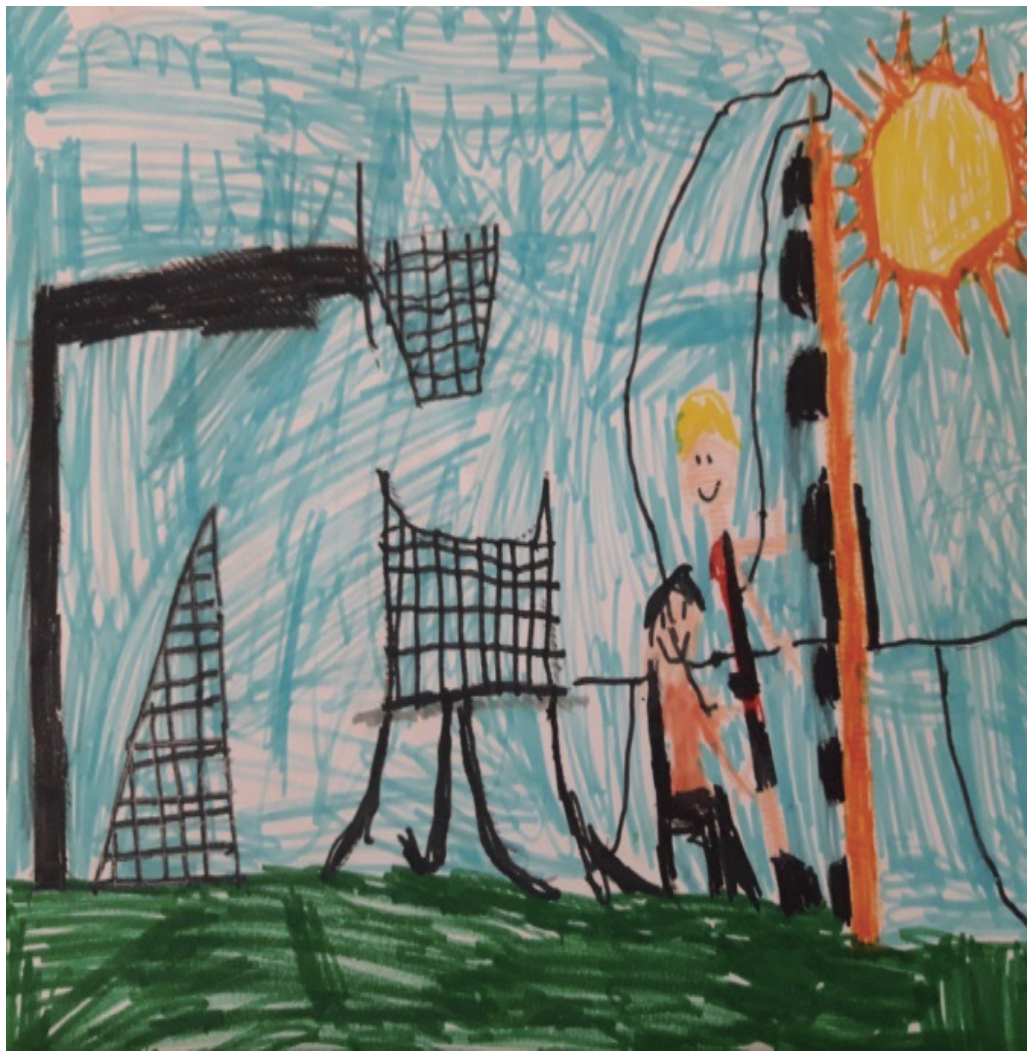

FONTE: ACERVO DOS AUTORES.

Ele desenhou a si próprio e nos mostrou que as pessoas com deficiência precisam ser vistas com olhar sensível e humano. Pelo desenho, notamos que o educando retratou a ajuda e o cuidado que recebeu para o desenvolvimento da atividade, fazendo-nos entender que a criança com deficiência precisa de apoio e de carinho para obter novas aprendizagens. O corpo da pessoa com deficiência é, assim como qualquer outro, condição de estar no mundo (MERLEAU-PONTY, 1996). Em suma, é preciso combater todo processo de violência que exclui os corpos deficientes na escola e na sociedade.

\section{ALGUMAS CONSIDERAÇÕES}

Incluir na educação é um processo constante de luta pelo reconhecimento e pela valorização da diversidade. As diferenças do ser humano não podem mais criar muros segregadores, mas sim pontes de encontros. O respeito às diferenças na escola é pauta para as discussões e as práticas pedagógicas. A escola deve ser um espaço acolhedor para cuidar dos corpos dos educandos com deficiência, incluindo-os nos processos educativos. Incluir é um desafio, uma atividade de aventura que exige dos seus participantes muita garra e afeto.

As vivências corporais retratadas nesse relato de experiência permitem questionar o lugar do corpo da pessoa com deficiência na escola, demonstrando que o estudante com deficiência tem o direito de ter acesso ao conhecimento da Educação Física. Esse relato infere que a Educação Física na escola colabora com a inclusão da criança com deficiência, ao oportunizar experiências corporais por meio das práticas de aventura, abrindo um mundo de possibilidades de movimentos e de novas aprendizagens. Julgamos que o corpo do estudante com deficiência precisa ser impactado e transformado. É preciso perder o medo de tocar, cuidar e amar o corpo da pessoa com deficiência. Ele possui sim algumas particularidades, mas continua sendo morada de um ser humano.

Propor atividades educacionais inclusivas na escola, como as que foram relatadas nesse texto, colabora para o desenvolvimento da cidadania e para a construção de uma sociedade democrática. Sendo 
assim, enfatizamos que é tarefa da Educação Física Escolar contribuir para a inclusão e para o desenvolvimento humano. A criança com deficiência tem o direito de ter acesso à cultura de movimento. Em suma, esse trabalho não esgota a discussão complexa em relação a inclusão. Esperamos inspirar os professores da área da Educação Física a pensarem ações pedagógicas inclusivas que toquem e explorem o corpo do estudante com deficiência. Novas experiências, novas aventuras e novos estudos são necessários para ajudar na consolidação da escola como um espaço de aprendizado e de vivências para todos.

\section{REFERÊNCIAS}

ADORNO, T. Educação e emancipação. 2. ed. Rio de Janeiro: Paz e Terra, 2000.

ALMEIDA, D. B.; TEIXEIRA, R. A. G. O contexto educacional complexo e diverso a partir de uma análise interpretativa dos aspectos legais que subsidiam propostas educativas inclusivas. In: LIBÂNEO, J. C.; SUANNO, M. V. R. (Orgs.). Didática e Escola em uma sociedade complexa. Goiânia: CEPED, 2011. p. 155-173.

BARRETO, C. S. G.; REIS, M. B. F. Educação inclusiva: do paradigma da igualdade para o paradigma da diversidade. Polyphonía, Goiânia, v. 22, n. 1, p. 19-32, jan./jun. 2011.

BOGDAN, R.; BIKLEN, S. K. Investigação qualitativa em Educação: uma introdução à teoria e aos métodos. Porto: Porto Editorial, 1994.

BUENO, J. G. S. Educação especial brasileira: integração/segregação do aluno diferente. São Paulo: EDUC, 1993.

CAMARGO, E. P. Inclusão social, educação inclusiva e educação especial: enlaces e desenlaces. Ciência e Educação, Bauru, v. 23, n. 1, p. 1-6, jan./mar. 2017.

CANEN, A. Universos culturais e representações docentes: subsídios para a formação de professores para a diversidade cultural. Educação e Sociedade, Campinas, v. 22, n. 77, p. 207-227, Dez. 2001.

COLETIVO DE AUTORES. Metodologia do Ensino de Educação Física. São Paulo: Cortez, 1992.

CORREIA, L. M. Inclusão e necessidades educativas especiais: um guia para educadores e professores. 2. ed. Porto: Porto Editora, 2008.

CORSARO, W. A. Sociologia da Infância. 2. ed. Porto Alegre: Artmed, 2011.

COSTA, V. A. Formação de professores e educação inclusiva frente às demandas humanas e sociais: para quê? In: MIRANDA, Theresinha Guimarães; FILHO, Teófilo Alves Galvão (Orgs.). O professor e a educação inclusiva: formação, práticas e lugares. Salvador: EDUFBA, 2012. p. 89-110.

DÍEZ, A. M. Traçando os mesmos caminhos para o desenvolvimento de uma educação inclusiva. Revista da Educação Especial, Brasília, v. 5, n. 1, p. 16-25, jan./jul. 2010.

FIGUEIREDO, R. V. A formação de professores para a inclusão dos alunos no espaço pedagógico da diversidade. In: MANTOAN, Maria Teresa Eglér (Org.). O desafio das diferenças nas escolas. 1. ed. Petrópolis: Vozes, 2013. p. 141-145.

FLICK, U. Introdução à pesquisa qualitativa. 3. ed. Porto Alegre: Artmed, 2009.

FOUCAULT, Michel. Microfísica do poder. 8. ed. Rio de Janeiro: Graal, 1979.

FOUCAULT, M. Vigiar e punir: nascimento da prisão. Petrópolis, Vozes, 1987.

FRANCO, L. C. P.; CAVASINI, R.; DARIDO, S. C. Práticas corporais de aventura. In: GONZÁLEZ, F. J.; DARIDO, S. C.; OLIVEIRA, A. A. B.(Orgs.). Lutas, capoeira e práticas corporais de aventura. Maringá: Eduem, 2014. p. 101-135.

GIL, A. C. Como elaborar projetos de pesquisa. 5. ed. São Paulo: Atlas, 2008. 
GOFFREDO, V. L. F. S. Integração ou segregação? eis a questão. In: MANTOAN, M.T. E. (Org.). A integração da pessoa com deficiência: contribuição para uma reflexão sobre o tema. São Paulo: Meminon, 1997. p. 230-235.

KUNZ, E. Transformação didático-pedagógica do esporte. Ijuí: Edição Unijuí, 1994.

LAZZAROTTI FILHO, L. A. et al. O termo práticas corporais na literatura científica brasileira e sua repercussão no campo da educação física. Movimento, Porto Alegre, v. 16, n. 1, p. 11-29, jan./mar. 2010.

LEVINAS, E. Totalidade e Infinito: ensaio sobre a exterioridade. Lisboa: Edições 70, 1980.

LIBÂNEO, J. C. Políticas educacionais no Brasil: desfiguramento da escola e do conhecimento escolar. Cadernos de Pesquisa, São Paulo, v. 46, n. 159, p. 38-62, jan./mar. 2016.

LIMA, F. J. Ética e inclusão o status da diferença. In: MARTINS, L.A. R. et al. (Orgs). Inclusão: compartilhando saberes. Petrópolis: Vozes, 2006. p. 54-66.

MANTOAN, M. T. E. Inclusão Escolar: O que é? Por Quê? Como Fazer? São Paulo: Moderna, 2003.

MARTINS, L. A. R. A visão de licenciandos sobre a formação inicial com vistas à atuação com a diversidade dos alunos. In: CAIADO, Katia Regina Moreno; JESUS, Denise Meyrelles; BAPTISTA, Claudio Roberto (Orgs.). Professores e educação especial: formação em foco. Porto Alegre: Mediação, 2011. p. 51-64.

MEIRIEU, P. O cotidiano da escola e da sala de aula: o fazer e o compreender. Porto Alegre: Artmed, 2005.

MERLEAU-PONTY, M. Fenomenologia da percepção. São Paulo: Martins Fontes, 1996.

MORIN, E. A cabeça bem-feita: repensar a reforma, reformar o pensamento. 23. ed. Rio de Janeiro: Bertrand Brasil, 2017.

MORIN, E.; DÍAZ, C. J. D. Reinventar a Educação: abrir caminhos para a metamorfose da humanidade. São Paulo: Pala Athena, 2016.

NICOLESCU, B. Nós, a partícula e o universo. Lisboa: Ésquilo, 2005.

PLETSCH, M. D. A formação de professores para a educação inclusiva: legislação, diretrizes políticas e resultados de pesquisas. Educar em Revista, Curitiba, v. 25, n. 33, p. 143-156, jan./abr. 2009.

REIS, M. B. F. Política pública, diversidade e formação docente: uma interface possível. 2013. Tese (Doutorado em Políticas Públicas, Estratégias e Desenvolvimento) - Instituto de Economia, Universidade Federal do Rio de Janeiro, Rio de Janeiro, 2013.

SANTOS, M. C. T. Inclusão escolar: desafios e perspectivas. In: MANTOAN, M. T. E. (Org.). O desafio das diferenças nas escolas. Petrópolis: Vozes, 2008. p. 147-152.

SANTOS, M. P. Formação de professores: exercitando propostas de inclusão. s.d. Disponível em:<https://www.academia.edu/24634763/FORMA\%C3\%87\%C3\%83O_DE_PROFESSORES_ EXERCITANDO_PROPOSTAS_DE_INCLUS\%C3\%83O > Acesso em: 20 Abr. 2020.

SANTOS, M. P. O papel do ensino superior na proposta de uma educação inclusiva. Movimento, Niterói, v. 1, n. 7, p.78-91, Maio. 2003.

SANTOS, P. L. A imagem enquanto fonte de pesquisa: a fotografia publicitária. Iniciação científica Cesumar, Maringá, v. 2, n. 2, p. 63-68, ago./dez. 2000.

SANTOS, T. P. Educando na diversidade: a questão da sala de recursos multifuncionais. 2017. Dissertação (Mestrado em Educação, Linguagem e Tecnologias) - Câmpus de ciências sócio-econômicas e humanas, Universidade Estadual de Goiás, Anápolis, 2017.

SILVA, A. B. B.; GAIATO, M. B.; REVELES, L. T. Mundo singular. Rio de janeiro: Objetiva, 2012. 
SILVA, A. M. et al. Corpo e experiência: para pensar as práticas corporais. In: FALCÃO, J. L. C.; SARAIVA, M. C. (Orgs.). Práticas corporais no contexto contemporâneo: (in)tensas experiências. Florianópolis: Copiart, 2009. p. 10-27.

TEIXEIRA, R. A. G. Matemática Inclusiva? O processo ensino-aprendizagem de matemática no contexto da diversidade. 2010. Tese (Doutorado em Educação) - Faculdade de Educação, Universidade Federal de Goiás, Goiânia, 2010.

TERRA, R. N.; GOMES, C. G. Inclusão escolar: carências e desafios na formação e atuação profissional. Revista Educação Especial, Santa Maria, v. 26, n. 45, p. 109-124, jan./abr. 2013. 